\title{
Mudanças no Uso da Terra na Amazônia Ocidental e a Resposta do Microclima à Ocorrência de Eventos Extremos
}

\author{
Jayne Soares Martins do Nascimento ${ }^{1}$ (D), Renata Gonçalves Aguiar ${ }^{1}$, Graciela Redies Fischer ${ }^{2}$, \\ Nara Luísa Reis de Andrade ${ }^{1}$, Leonardo José Gonçalves Aguiar ${ }^{2}$, Alberto Dresch Webler ${ }^{1}$ \\ ${ }^{1}$ Departamento de Engenharia Ambiental, Universidade Federal de Rondônia, Ji-Paraná, RO, \\ Brasil. \\ ${ }^{2}$ Departamento de Meteorologia, Universidade Federal de Pelotas, Pelotas, RS, Brasil.
}

Recebido em: 2 de Agosto de 2019 - Aceito em: 12 de Setembro de 2019

\begin{abstract}
Resumo
Os relatórios do Painel Intergovernamental Sobre Mudanças Climáticas constantemente divulgam a possibilidade de que a ocorrência de extremos climáticos seja maior nos próximos anos. A Região Amazônica tem experimentado esses eventos com frequência, o que tem contribuído para que mais estudos acerca de sua susceptibilidade sejam realizados. Esse estudo objetivou identificar a resposta do microclima às secas de 2005 e 2010 em áreas de floresta nativa e de pastagem na Amazônia Ocidental por meio da análise da umidade específica do ar, temperatura do ar e saldo de radiação. Os dados utilizados são provenientes de torres pertencentes ao Programa de Grande Escala da Biosfera-Atmosfera na Amazônia. Os resultados indicam que nos anos estudados houveram alterações significativas nas variáveis estudadas em ambos os sítios, com reduções de aproximadamente $16 \%$ na umidade específica e aumentos de até 3,76\% na temperatura. Entretanto, os efeitos da seca de 2010 podem ter sido amenizados na floresta devido ao evento ser precedido por um evento extremo de cheia (2009). Os resultados evidenciam o quanto a conversão de áreas de floresta para pastagem, aliado aos eventos extremos, pode interferir nas variáveis meteorológicas, sendo imprescindível o contínuo estudo dessa dinâmica para que as implicações microclimáticas sejam elucidadas.
\end{abstract}

Palavras-chave: Floresta tropical, extremos climáticos, seca na Amazônia.

\section{Changes in Land Use in the Western Amazon and the Microclima's Response to the Occurrence of Extreme Events}

\begin{abstract}
The reports of the Intergovernmental Panel on Climate Change constantly reveal the possibility that climatic extremes will increase in the coming years. The Amazon Region has experienced these events frequently, which has contributed to the fact that more studies about its susceptibility are carried out. This study aimed to identify the microclimate response to droughts of 2005 and 2010 in areas of native forest and pasture in the Western Amazon by analyzing specific air humidity, air temperature and net radiation. The data used come from towers belonging to Large Scale Biosphere-Atmosphere Experiment in Amazonia. The results indicate that in the years studied there were significant changes in the variables studied at both sites, with reductions of approximately $16 \%$ in specific humidity and increases of up to $3.76 \%$ in temperature. However, the effects of the 2010 drought may have been softened in the forest due to the event being preceded by an extreme flood event (2009). The results show that the conversion of forest areas to pasture, together with extreme events, can interfere in the meteorological variables, being necessary the continuous study of this dynamics for the microclimatic implications to be elucidated.
\end{abstract}

Keywords: Tropical forests, climatic extremes, drought in the Amazon.

Autor de correspondência: Jayne Soares Martins do Nascimento, jayne_smn@hotmail.com. 


\section{Introdução}

O desmatamento da Floresta Amazônica é um dos mais importantes objetos de preocupação ambiental das últimas décadas. Os elevados índices de desmatamento têm despertado preocupação entre os cientistas acerca do cenário climático futuro. Aliado ao processo de expansão agrícola acelerado, a Amazônia, por sua grande área, é um ecossistema altamente susceptível em escalas regionais e globais (Borma et al., 2013).

Somado a isso, a Floresta Amazônica vem sofrendo sérias ameaças à sua resiliência em resposta às mudanças climáticas globais, que poderão tornar a região gradativamente mais quente e seca, podendo atingir patamares de não conseguir manter uma vegetação de grande porte (Fearnside, 2009). Nesse contexto, a ocorrência cada vez mais frequente de extremos climáticos é um dos panoramas mais divulgados pelos relatórios do Painel Intergovernamental Sobre Mudanças Climáticas (IPCC Intergovernmental Panel on Climate Change, 2014).

A Amazônia tem experimentado esses eventos em intervalo de tempo relativamente curto. A região enfrentou dois eventos de seca extrema no intervalo de cinco anos, um em 2005 e outro em 2010 (Marengo et al., 2011a; Marengo et al., 2011b), sendo esse último reconhecido como o mais drástico dos últimos 110 anos (INPE, 2011; Marengo et al., 2013).

$\mathrm{Na}$ Região Amazônica os eventos extremos de seca estão estritamente relacionados à eventos climáticos de grande escala, tais como o El Niño, o aquecimento anormal da superfície do Attântico Norte ou ainda por ambos, conforme mencionado por vários autores (Borma et al., 2013; Coelho et al., 2012; Marengo et al., 2008). O primeiro é bastante influente na precipitação durante a estação chuvosa e o segundo na duração e intensidade da estação seca da região (Harris et al., 2008; Li et al., 2006), o que contribui com a redução do fluxo de descarga do rio Amazonas na estação seca, como pôde ser observado em 2010 (Marengo et al., 2011a; Marengo et al., 2011b).

Os eventos extremos alteram drasticamente o cotidiano das pessoas, causando impactos na economia, além de, em casos mais graves, deixar vítimas fatais (Coelho et al., 2012; Silva-Dias, 2014). Adicionalmente, esses eventos podem ocasionar a degradação e diminuição da vegetação natural da Amazônia, podendo trazer sérias consequências para a população regional e mundial, como a perda de biodiversidade, alterações nas dinâmicas das chuvas, do balanço de carbono, bem como dos serviços ecossistêmicos fornecidos pela floresta (Artaxo et al., 2014), transporte de umidade e calor para as médias latitudes.

Além das variações na temperatura do ar e no regime de chuvas devido ao desmatamento (Lawrence; Vandecar, 2015), têm-se a intervenção gerada pela ocorrência de eventos extremos que pode não somente alterar a dinâmica microclimática, como também trazer agravos à saúde humana, prejudicar as atividades agropecuárias, sendo, portanto, relevante destacar alguns impactos que podem advir em decorrência da interferência ocasionada pelos eventos extremos na Região Amazônica, sobretudo eventos de seca.

Mediante o exposto, o presente estudo objetivou identificar a resposta do microclima à ocorrência das secas de 2005 e 2010 em uma área de floresta nativa e em uma área de pastagem na Amazônia Ocidental, por meio da análise das variações temporais de umidade específica do ar, temperatura do ar e saldo de radiação.

\section{Materiais e Métodos}

$\mathrm{O}$ estudo foi realizado em uma área de floresta tropical úmida (Reserva Biológica do Jaru - Rebio Jaru) e em uma área de pastagem (Fazenda Nossa Senhora - FNS), ambas localizadas no estado de Rondônia.

A Rebio Jaru (10¹1'11,4” S; 6152’29,9”'W) está localizada na porção Leste do estado de Rondônia e abrange áreas dos municípios de Ji-Paraná, Machadinho d'Oeste e Vale do Anari, totalizando 353.000 ha. É composta por vegetação nativa e foi classificada como Floresta Ombrófila Aberta de terra firme (Culf et al., 1997), com altura média do dossel de aproximadamente $30 \mathrm{~m}$, com ocorrência de árvores emergentes de até $45 \mathrm{~m}$ (Rummel et al., 2002). Possui precipitação média anual entre 1.843 e $2.008 \mathrm{~mm} \mathrm{ano}^{-1}$ (Franca, 2015).

A FNS está situada na zona rural do município de Ouro Preto do Oeste $\left(10^{\circ} 45^{\prime} 44^{\prime \prime} \mathrm{S}, 62^{\circ} 21^{\prime} 27^{\prime \prime} \mathrm{W}\right)$, a aproximadamente $11 \mathrm{~km}$ da zona urbana do município. A área foi desmatada no ano de 1977, com aproximadamente $50 \mathrm{~km}$ de raio e situa-se na maior área plana com pastagem na região, com área total de $4 \mathrm{~km}^{2}$ e $220 \mathrm{~m}$ de altitude (Culf et al., 1997). É predominantemente composta pela gramínea Brachiaria brizantha, além de algumas palmeiras dispersas e fragmentos florestais, com precipitação média de $1.627 \mathrm{~mm}$ ano $^{-1}$ (Webler et al., 2013).

Em cada sítio está instalada uma torre micrometeorológica, sendo ambas pertencentes à rede de torres do Programa de Grande Escala da Biosfera-Atmosfera na Amazônia - LBA. Para a realização deste estudo foram utilizadas medidas de saldo de radiação $(\mathrm{Rn})$, temperatura (T), umidade relativa do ar (UR) e pressão atmosférica (Pa) correspondente aos anos de 2004 a 2010. Os anos de 2005 e 2010 foram considerados como sendo de extrema seca enquanto os demais foram considerados anos normais, exceto pelo ano de 2009 , por apresentar elevada taxa de precipitação na estação úmida foi retirado da análise.

Os sensores utilizados para medir as respectivas variáveis bem como sua disposição nas torres estão descritos na Tabela 1.

A umidade específica do ar $(q)$, a pressão real de vapor d'água $(e)$ e a pressão de saturação do vapor d'água 
Tabela 1 - Relação de variáveis, instrumentos instalados e respectivas alturas nas torres das áreas de floresta (Rebio Jaru) e pastagem (FNS).

\begin{tabular}{|c|c|c|c|}
\hline \multirow[t]{2}{*}{ Variável micrometeorológica } & \multirow[t]{2}{*}{ Instrumento } & \multicolumn{2}{|c|}{ Altura do sensor } \\
\hline & & Rebio Jaru & FNS \\
\hline Saldo de radiação $(\mathrm{Rn})$ & Saldo radiômetro, NR-Lite 1, Kipp\&Zonen, NLD & $58 \mathrm{~m}$ & $6,5 \mathrm{~m}$ \\
\hline Temperatura (T) e umidade relativa do ar (UR) & Termohigrômetro HMP35A (Rebio Jaru) e HMP45C (FNS), Vaisala, FIN & $61,5 \mathrm{~m}$ & $8 \mathrm{~m}$ \\
\hline Pressão atmosférica $(\mathrm{Pa})$ & Barômetro PTB100A, Vaisala, FIN & $61 \mathrm{~m}$ & $1,5 \mathrm{~m}$ \\
\hline
\end{tabular}

(es) foram calculadas respectivamente pelas Eqs. (1)-(3).

$$
\begin{gathered}
q=\frac{0,622 \times e}{P a-0,378 \times e} \times 1000 \\
e=\frac{U R \times e s}{100} \\
e s=6,1078 \times 10^{\left[\frac{7,5 \times T}{237,3+T}\right]}
\end{gathered}
$$

sendo $q$ a umidade específica do $\operatorname{ar}\left(\mathrm{g} \mathrm{kg}^{-1}\right), e$ a pressão real do vapor d'água $(\mathrm{hPa}), P a$ a pressão atmosférica (hPa), UR a umidade relativa do ar (\%), es a pressão de saturação do vapor d'água $(\mathrm{hPa})$ e $T$ a temperatura do ar $\left({ }^{\circ} \mathrm{C}\right)$.

Para a análise estatística foram calculadas médias para os períodos úmido (janeiro a março), de transição úmido-seco (abril a junho), seco (julho a setembro) e de transição seco-úmido (outubro a dezembro). Os anos de 2005 e 2010 foram analisados individualmente e os de 2004, 2006, 2007 e 2008, considerados anos normais, sem ocorrência de eventos extremos de seca ou elevada precipitação acumulada, foram analisados em conjunto.

Em decorrência das séries de dados das variáveis analisadas não terem apresentado distribuição normal (pressuposto verificado através do teste de Shapiro-Wilk, $\alpha=0,05$ ), os intervalos de confiança (IC) de $95 \%$ foram construídos utilizando a técnica de reamostragem bootstrap com 1.000 replicações.

A variabilidade percentual entre o ano extremo (2005 ou 2010) e os anos normais foi obtida por meio da Eq. (4).

$$
V=\frac{\bar{x}_{\text {Ano extremo }}}{\bar{x}_{\text {Anos normais }}} \times 100
$$

onde $V$ é a variabilidade entre o ano extremo e os anos normais (\%), $\bar{x}_{\text {Ano extremo }}$ é a média de determinada variável durante o ano extremo (2005 ou 2010) e $\bar{x}_{\text {Anos normais }}$ é a média da variável respectiva durante os anos normais. A diferença para mais ou para menos em relação à referência adotada foi indicada pelos sinais de mais (+) e menos (-), respectivamente.

Além do pressuposto da normalidade, foi verificado o de homocedasticidade das amostras através do teste F. Como esses pressupostos não foram atendidos, foi apli- cado o teste estatístico não paramétrico de WilcoxonMann-Whitney para amostras independentes $(\alpha=0,05)$ para verificar se as médias entre anos normais e extremos apresentam diferenças significativas com auxílio do programa Minitab 17.

\section{Resultados e Discussão}

\subsection{Umidade específica do ar}

Apesar de o ano de 2010 ter sido marcado por extrema seca, conforme documentado na literatura, a umidade específica do ar na área de floresta foi significativamente superior ( $\mathrm{p}$-valor $<0,001$ ) comparada aos anos normais durante os períodos úmido e úmido-seco (Tabela 2), resultado este condizente com o estudo de Oliveira (2014) que constatou no sítio experimental alto índice pluviométrico durante o ano de 2010.

Oliveira (2014) identificou para os anos de 1999 a 2012 alta frequência de eventos de precipitação de baixa escala $(0,0$ a $15,0 \mathrm{~mm})$, os quais desfavorecem o escoamento superficial rápido, contribuindo com a recarga dos aquíferos. Dessa forma, o fato de o evento de seca (2010) ter sido precedido por um evento de cheia (2009) corroborou para que a umidade específica tenha permanecido alta, uma vez que a disponibilidade de água no solo não estava comprometida devido à recente recarga do lençol freático. $\mathrm{Na}$ floresta a água subterrânea é acessível às árvores devido suas longas raízes terem a capacidade de aproveitar a água nas camadas mais profundas do solo.

$\mathrm{O}$ ano de 2005 , ao contrário, permaneceu com precipitação baixa durante todo o ano, conforme mencionado em estudos sobre a Região Amazônica (Marengo et al., 2011a; Marengo et al., 2011b; Oliveira, 2014), o que refletiu em uma redução altamente significativa ( $p$-valor < 0,001) da umidade específica do ar na área de floresta.

Ao comparar a umidade específica dos períodos seco e úmido observou-se que no período seco de anos normais a umidade foi significativamente reduzida em -16,97\% (pvalor $<0,001)$. Esse valor difere do encontrado por von Randow et al. (2004) no mesmo sítio experimental, que identificaram umidade específica média no período seco 9,71\% inferior em relação ao período úmido entre os anos de 1999 a 2002. No ano de 2010, a diferença entre os períodos úmido e seco foi de $-24,37 \%$ (p-valor $<0,001$ ). Entretanto, em termos de magnitude, os valores encontrados no presente estudo estão muito próximos aos obti- 
dos por von Randow et al. (2004), que foram de 17,50 g $\mathrm{kg}^{-1}$ e $15,80 \mathrm{~g} \mathrm{~kg}^{-1}$ nos períodos úmido e seco, respectivamente.

Por sua vez, no sítio de pastagem a umidade específica do ar foi significativamente reduzida nos dois anos de extrema seca, principalmente no período seco (p-valor < 0,001), conforme disposto na Tabela 3.

Comparando os valores de umidade específica do ar dos períodos seco e úmido foi constatado que a umidade no período seco foi significativamente menor ( $\mathrm{p}$-valor $<$

Tabela 2 - Valores médios de umidade específica do ar $\left(\mathrm{q}, \mathrm{g} \mathrm{kg}^{-1}\right)$ por período em diferentes anos no sítio de floresta, medidas descritivas, diferença ao comparar os anos de extrema seca (2005 e 2010) com os normais $(2004,2006,2007$ e 2008) e os respectivos testes de hipótese de comparação de médias $(\alpha=0,05)$.

\begin{tabular}{|c|c|c|c|c|c|}
\hline Anos & $\bar{x}$ & IC & s & Diferença (\%) Anos extremos/anos normais & p-valor \\
\hline \multicolumn{6}{|c|}{ Período úmido } \\
\hline Normais & 17,27 & {$[17,26 ; 17,28]$} & 0,80 & - & - \\
\hline 2005 & - & - & - & - & - \\
\hline 2010 & 18,26 & {$[18,24 ; 18,28]$} & 0,83 & $+5,73$ & $<0,001$ \\
\hline \multicolumn{6}{|c|}{ Período úmido-seco } \\
\hline Normais & 15,70 & {$[15,67 ; 15,72]$} & 2,03 & - & - \\
\hline 2005 & - & - & - & - & - \\
\hline 2010 & 16,26 & {$[16,20 ; 16,32]$} & 2,68 & $+3,57$ & $<0,001$ \\
\hline \multicolumn{6}{|c|}{ Período seco } \\
\hline Normais & 14,34 & {$[14,32 ; 14,36]$} & 2,07 & - & - \\
\hline 2005 & 13,54 & {$[15,50 ; 13,58]$} & 2,27 & $-5,57$ & $<0,001$ \\
\hline 2010 & 13,81 & {$[13,77 ; 13,86]$} & 2,76 & $-4,10$ & $<0,001$ \\
\hline \multicolumn{6}{|c|}{ Período seco-úmido } \\
\hline Normais & 17,04 & {$[17,03 ; 17,05]$} & 1,05 & - & - \\
\hline 2005 & 16,15 & {$[16,13 ; 16,17]$} & 0,93 & $-5,22$ & $<0,001$ \\
\hline 2010 & 16,94 & {$[16,94 ; 16,98]$} & 1,20 & $-0,59$ & $<0,001$ \\
\hline
\end{tabular}

Notas: $\bar{x}$ - média; IC - intervalo de confiança; s - desvio padrão; p-valor - nível de significância observado. O p-valor foi calculado por meio de teste de hipótese entre os anos extremos e os anos normais. Dados indisponíveis foram substituídos por hífen (-).

Tabela 3 - Valores médios de umidade específica do ar ( $\left.\mathrm{q}, \mathrm{g} \mathrm{kg}^{-1}\right)$ por período em diferentes anos no sítio de pastagem, medidas descritivas, diferença ao comparar os anos de extrema seca (2005 e 2010) com os normais (2004, 2006, 2007 e 2008) e os respectivos testes de hipótese de comparação de médias $(\alpha=0,05)$.

\begin{tabular}{|c|c|c|c|c|c|}
\hline Anos & $\bar{x}$ & IC & $\mathrm{s}$ & Diferença (\%) Anos extremos/anos normais & p-valor \\
\hline \multicolumn{6}{|c|}{ Período úmido } \\
\hline Normais & 16,02 & {$[16,05 ; 16 ; 07]$} & 0,78 & - & - \\
\hline 2005 & 16,42 & {$[16,40 ; 16,44]$} & 0,95 & $+2,50$ & $<0,001$ \\
\hline 2010 & - & - & - & - & - \\
\hline \multicolumn{6}{|c|}{ Período úmido-seco } \\
\hline Normais & 14,15 & {$[14,13 ; 14,17]$} & 2,06 & - & - \\
\hline 2005 & 15,20 & {$[15,17 ; 15,23]$} & 1,59 & $+7,42$ & $<0,001$ \\
\hline 2010 & 13,67 & {$[13,61 ; 13,72]$} & 2,59 & $-3,39$ & $<0,001$ \\
\hline \multicolumn{6}{|c|}{ Período seco } \\
\hline Normais & 12,27 & {$[12,24 ; 12,29]$} & 2,16 & - & - \\
\hline 2005 & 11,54 & {$[11,50 ; 11,59]$} & 2,38 & $-5,95$ & $<0,001$ \\
\hline 2010 & 10,32 & {$[10,26 ; 10,38]$} & 2,77 & $-15,89$ & $<0,001$ \\
\hline \multicolumn{6}{|c|}{ Período seco-úmido } \\
\hline Normais & 15,59 & {$[15,58 ; 15,60]$} & 1,06 & - & - \\
\hline 2005 & 15,62 & {$[15,61 ; 15 ; 64]$} & 0,83 & $-0,19$ & $<0,001$ \\
\hline 2010 & 14,97 & {$[14,95 ; 15,00]$} & 1,15 & $-3,98$ & $<0,001$ \\
\hline
\end{tabular}

Notas: $\bar{x}$ - média; IC - intervalo de confiança; s - desvio padrão; p-valor - nível de significância observado. O p-valor foi calculado por meio de teste de hipótese entre os anos extremos e os anos normais. Dados indisponíveis foram substituídos por hífen (-). 
0,001 ), sendo de $-23,41 \%$ em anos normais e de $-29,72 \%$ em 2005 (Tabela 3).

Os valores aqui apresentados se assemelham aos divulgados no estudo realizado por Webler et al. (2013), que encontraram umidade específica média no período seco $-21,34 \%$ inferior em relação ao período úmido ao estudar a mesma área de pastagem no período de 2000 a 2005 (visto que cinco desses anos são considerados normais).

Essa significativa redução da umidade específica no período seco ( $\mathrm{p}$-valor $<0,001$ ) se deve principalmente ao menor índice pluviométrico característico do período, mas também pela brusca redução da umidade do ar acarretada pelos eventos de friagem, que frequentemente atingem a região durante o período seco.

Ao comparar os sítios experimentais (Tabela 4), a umidade específica permaneceu inferior na área de pastagem. Tal comportamento era esperado, uma vez que ecossistemas florestais possuem índice pluviométrico superior em relação às áreas de pastagem, o que proporciona maior evapotranspiração nesses locais (Gomes et al., 2015).

$\mathrm{O}$ ano de 2010 foi o que apresentou as maiores diferenças significativas na umidade específica ( $\mathrm{p}$-valor < 0,001 ), sendo que o período seco obteve a maior redução no sítio de pastagem, $-25,27 \%$. Esse resultado reforça a maior susceptibilidade de áreas de pastagem à ocorrência de eventos de extrema seca, uma vez que o sistema radicular da vegetação predominante é curto, não alcançando os níveis mais profundos onde o lençol freático se encontra.
Tavares (2012) elucida que em áreas de floresta há maior emissão de partículas, as quais atuam como núcleos de condensação, favorecendo a precipitação nesses locais. Estudo recente realizado por Wang et al. (2016) relata que os aerossóis atmosféricos situados a cerca de 15 mil metros de altitude se juntam às partículas provenientes das árvores e alimentam as nuvens que dão origem às chuvas na Região Amazônica. Os autores relatam que o forte gradiente vertical na concentração de partículas existente na floresta proporciona o elevado índice pluviométrico característico da região.

Por outro lado, a floresta consegue manter altas taxas de evapotranspiração mesmo após longos períodos de seca, propiciado pelo aproveitamento hídrico das camadas mais profundas do solo (von Randow et al., 2004), uma vez que as árvores da Floresta Amazônica são capazes de retirar água de até 8 metros de profundidade (Nepstad et al., 1994). O acesso às águas profundas é responsável por aumentar em aproximadamente $40 \%$ a transpiração na estação seca, visto que a vegetação da floresta consegue ter acesso à água no solo não disponível para gramíneas e culturas agrícolas (Nepstad et al., 1994).

\subsection{Temperatura do ar}

Com a ocorrência dos eventos de extrema seca nos anos de 2005 e 2010 , a temperatura do ar apresentou aumento significativo ( $\mathrm{p}$-valor $<0,001$ ) para praticamente todos os períodos do ano comparado aos anos normais no sítio de floresta, exceto no período seco (Tabela 5). A

Tabela 4 - Valores médios de umidade específica do ar (q, $\left.\mathrm{g} \mathrm{kg}^{-1}\right)$ por período em anos normais $(2004,2006,2007$ e 2008) e de extrema seca (2005 e 2010) nos sítios de floresta (Rebio Jaru) e de pastagem (FNS), diferença ao comparar os sítios experimentais e respectivos testes de hipótese de comparação de médias $(\alpha=0,05)$.

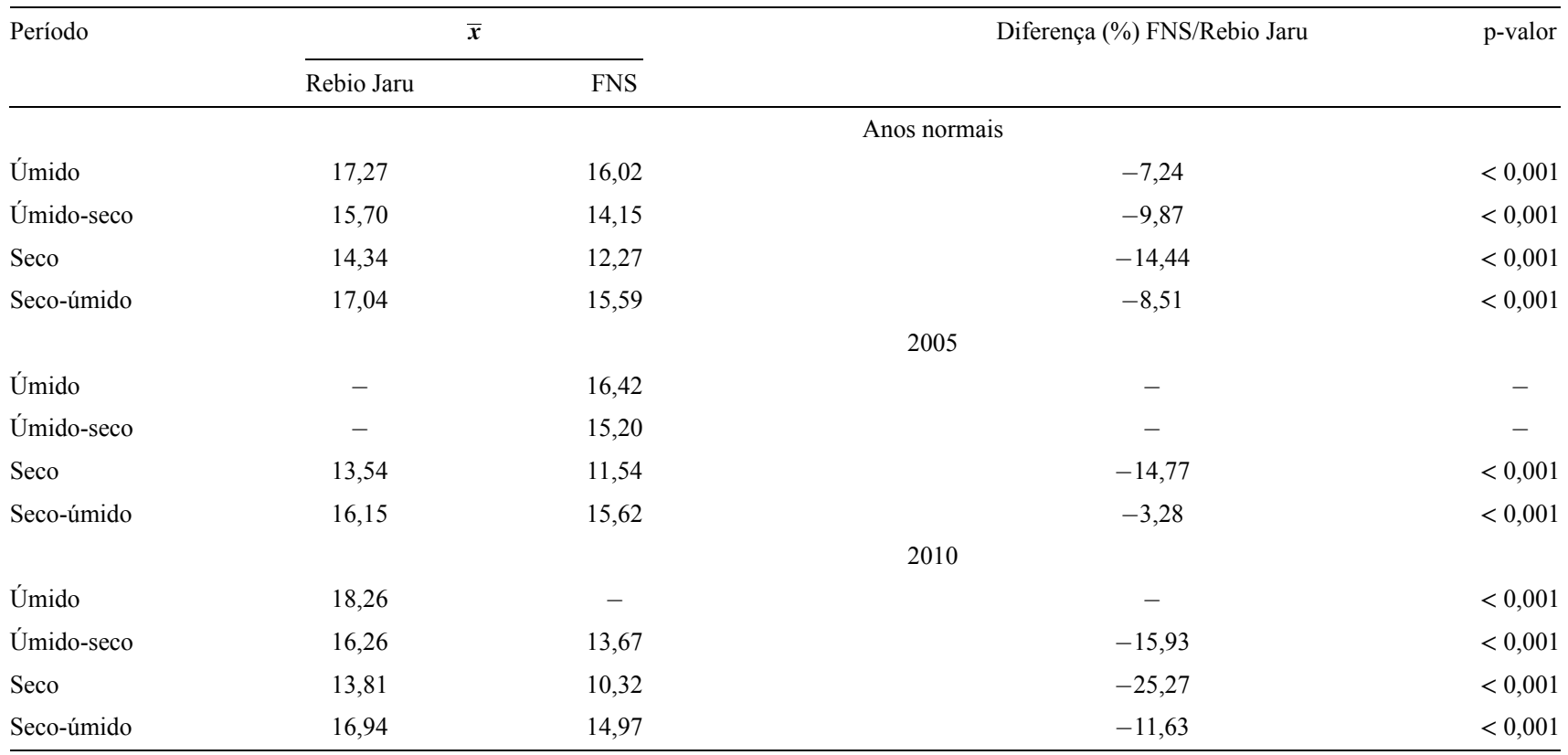

Notas: $\bar{x}$ - média; p-valor - nível de significância observado. O p-valor foi calculado por meio de teste de hipótese entre os sítios de floresta e de pastagem. Dados indisponíveis foram substituídos por hífen (-). 
maior diferença em relação aos anos normais foi encontrada no ano de 2010 para os períodos úmido $(+2,64 \%)$ e úmido-seco $(+3,76 \%)$.

No período seco a temperatura foi significativamente maior ( $\mathrm{p}$-valor $<0,001$ ) do que no período úmido, apresentando diferença de $+7,40 \%$ em anos normais e de $+3,86 \%$ no ano de 2010. Negrón-Juarez et al. (2007) destacam que o aumento na temperatura do ar acarreta elevação da transpiração e evaporação de água na superfície, aumentando assim a umidade do ar, desde que haja água disponível no solo para o processo de evapotranspiração.

No sítio de pastagem a temperatura do ar também foi predominantemente maior nos anos de extrema seca (Tabela 6). Entretanto, a maior média diária $(25,6$ [25,6; $25,7]^{\circ} \mathrm{C}$ ) foi observada no período seco dos anos normais. Ao comparar o período seco com o período úmido, o maior aumento percentual foi observado nos anos normais, quando apresentou média diária $+4,36 \%$ superior no período seco.

Os anos extremos, apesar da terem menor variabilidade sazonal, apresentaram maior desvio padrão no conjunto de dados em todos os períodos, conforme demonstrado na Tabela 6. Esse comportamento é resultante da significativa redução da umidade específica do ar (Tabelas 2 e 3), que altera a partição do balanço de energia, acarreta uma maior fração de calor sensível e proporciona maiores amplitudes térmicas.

Em termos de área de estudo, a ocorrência de eventos extremos influenciou significativamente ( $p$-valor $<0,001$ ) o microclima da área de pastagem durante os períodos seco e seco-úmido, indicando maior vulnerabilidade desse ecossistema nos períodos mencionados. Por sua vez, durante os períodos úmido e úmido-seco a influência foi maior no sítio de floresta em resposta ao acúmulo de calor absorvido pela umidade contida na atmosfera. Essa dinâmica fez com que o índice de precipitação no período úmido de 2010 permanecesse alto (Oliveira, 2014), mesmo com o evento de seca ocorrido no referido ano.

\subsection{Saldo de radiação}

$\mathrm{Na}$ área de floresta, os anos de eventos extremos, apresentaram saldo de radiação médio predominantemente superior comparado à média dos anos normais (Tabela 7), exceto para os períodos úmido e seco de 2010. Ao comparar com os anos normais, 2005 apresentou significativo aumento do saldo de radiação, sobretudo nos períodos seco e seco-úmido. Esse comportamento pode ter sido causado tanto por uma menor cobertura de nuvens nos períodos seco e seco-úmido, o que acarretaria em maior incidência da radiação solar à superfície, quanto por uma maior perda de área foliar pela floresta devido à seca mais severa, resultando em uma maior infiltração da radiação solar ao longo do dossel.

A estrutura da floresta permite um eficiente aproveitamento da radiação solar incidente, mesmo em anos de eventos extremos, conforme elucidado no estudo de Davidson et al. (2012). Os autores destacam, no entanto, que ao ser submetida a perturbações repetidas e prolongadas a floresta pode ter sua estrutura potencialmente alterada, tanto na composição da vegetação quanto no armaze-

Tabela 5 - Valores médios de temperatura do ar $\left({ }^{\circ} \mathrm{C}\right)$ por período em diferentes anos no sítio de floresta, medidas descritivas, diferença ao comparar os anos de extrema seca (2005 e 2010) com os normais $(2004,2006,2007$ e 2008) e os respectivos testes de hipótese de comparação de médias $(\alpha=0,05)$.

\begin{tabular}{|c|c|c|c|c|c|}
\hline Anos & $\bar{x}$ & IC & s & Diferença (\%) Anos extremos/anos normais & p-valor \\
\hline & \multicolumn{5}{|c|}{ Período úmido } \\
\hline Normais & 25,0 & {$[25,0 ; 25,0]$} & 2,32 & - & - \\
\hline 2005 & - & - & - & - & - \\
\hline \multirow[t]{2}{*}{2010} & 25,7 & {$[25,6 ; 25,7]$} & 2,32 & $+2,64$ & $<0,001$ \\
\hline & \multicolumn{5}{|c|}{ Período úmido-seco } \\
\hline Normais & 24,7 & {$[24,7 ; 24,8]$} & 3,47 & - & - \\
\hline 2005 & - & - & - & - & - \\
\hline \multirow[t]{2}{*}{2010} & 25,6 & {$[25,6 ; 25,7]$} & 3,80 & $+3,76$ & $<0,001$ \\
\hline & \multicolumn{5}{|c|}{ Período seco } \\
\hline Normais & 26,9 & {$[26,8 ; 26,9]$} & 4,04 & - & - \\
\hline 2005 & 26,3 & {$[26,2 ; 26,4]$} & 4,43 & $-2,12$ & $<0,001$ \\
\hline \multirow[t]{2}{*}{2010} & 26,7 & {$[26,6 ; 26,7]$} & 4,96 & $-0,74$ & $<0,001$ \\
\hline & \multicolumn{5}{|c|}{ Período seco-úmido } \\
\hline Normais & 25,8 & {$[25,8 ; 25,8]$} & 2,86 & - & - \\
\hline 2005 & 26,0 & {$[26,0 ; 26,1]$} & 3,02 & $+1,01$ & $<0,001$ \\
\hline 2010 & 26,1 & {$[26,0 ; 26,2]$} & 3,25 & $+1,20$ & $<0,001$ \\
\hline
\end{tabular}

Notas: $\bar{x}$ - média; IC - intervalo de confiança; $\mathrm{s}$ - desvio padrão; $\mathrm{p}$-valor - nível de significância observado. O p-valor foi calculado por meio de teste de hipótese entre os anos extremos e os anos normais. Dados indisponíveis foram substituídos por hífen (-). 
Tabela 6 - Valores médios de temperatura do ar $\left({ }^{\circ} \mathrm{C}\right)$ por período em diferentes anos no sítio de pastagem, medidas descritivas, diferença ao comparar os anos de extrema seca (2005 e 2010) com os normais $(2004,2006,2007$ e 2008) e os respectivos testes de hipótese de comparação de médias $(\alpha=0,05)$.

\begin{tabular}{|c|c|c|c|c|c|}
\hline Anos & $\bar{x}$ & IC & $\mathrm{s}$ & Diferença (\%) Anos extremos/anos normais & p-valor \\
\hline & \multicolumn{5}{|c|}{ Período úmido } \\
\hline Normais & 24,5 & {$[24,5 ; 24,6]$} & 2,35 & - & - \\
\hline 2005 & 24,9 & {$[24,9 ; 25,0]$} & 2,49 & $+1,47$ & $<0,001$ \\
\hline \multirow[t]{2}{*}{2010} & 25,0 & {$[24,9 ; 25,0]$} & 2,52 & $+1,75$ & $<0,001$ \\
\hline & \multicolumn{5}{|c|}{ Período úmido-seco } \\
\hline Normais & 23,6 & {$[23,6 ; 23,6]$} & 3,67 & - & - \\
\hline 2005 & 24,8 & {$[24,7 ; 24,9]$} & 3,65 & $+5,17$ & $<0,001$ \\
\hline \multirow[t]{2}{*}{2010} & 24,3 & {$[24,2 ; 24,4]$} & 4,13 & $+3,09$ & $<0,001$ \\
\hline & \multicolumn{5}{|c|}{ Período seco } \\
\hline Normais & 25,6 & {$[25,6 ; 25,7]$} & 4,58 & - & - \\
\hline 2005 & 25,1 & {$[25,0 ; 25,2]$} & 4,96 & $-1,95$ & $<0,001$ \\
\hline \multirow[t]{2}{*}{2010} & 24,8 & {$[24,7 ; 24,9]$} & 5,82 & $-3,20$ & $<0,001$ \\
\hline & \multicolumn{5}{|c|}{ Período seco-úmido } \\
\hline Normais & 25,1 & {$[25,1 ; 25,1]$} & 2,96 & - & - \\
\hline 2005 & 25,4 & {$[25,3 ; 25,5]$} & 3,05 & $+1,12$ & $<0,001$ \\
\hline 2010 & 25,5 & {$[25,5 ; 25,6]$} & 3,40 & $+1,75$ & $<0,001$ \\
\hline
\end{tabular}

Notas: $\bar{x}$ - média; IC - intervalo de confiança; $\mathrm{s}$ - desvio padrão; p-valor - nível de significância observado. O p-valor foi calculado por meio de teste de hipótese entre os anos extremos e os anos normais. Dados indisponíveis foram substituídos por hífen (-).

Tabela 7 - Valores médios de saldo de radiação $\left(\mathrm{MJ} \mathrm{m}^{-2} \mathrm{dia}^{-1}\right)$ por período em diferentes anos no sítio de floresta, medidas descritivas, diferença ao comparar os anos de extrema seca (2005 e 2010) com os normais $(2004,2006,2007$ e 2008) e os respectivos testes de hipótese de comparação de médias $(\alpha=$ $0,05)$.

\begin{tabular}{|c|c|c|c|c|c|}
\hline Anos & $\bar{x}$ & IC & $\mathrm{s}$ & Diferença (\%) Anos extremos/anos normais & p-valor \\
\hline & \multicolumn{5}{|c|}{ Período úmido } \\
\hline Normais & 10,53 & {$[10,05 ; 11,03]$} & 3,95 & - & - \\
\hline 2005 & - & - & - & - & - \\
\hline \multirow[t]{2}{*}{2010} & 10,46 & {$[9,68 ; 11,21]$} & 3,63 & $-0,66$ & $<0,001$ \\
\hline & \multicolumn{5}{|c|}{ Período úmido-seco } \\
\hline Normais & 10,03 & {$[9,55 ; 10,45]$} & 3,39 & - & - \\
\hline 2005 & 11,26 & {$[10,37 ; 11,94]$} & 2,35 & $+12,26$ & $<0,001$ \\
\hline \multirow[t]{2}{*}{2010} & 11,46 & {$[10,80 ; 12,08]$} & 2,47 & $+14,26$ & $<0,001$ \\
\hline & \multicolumn{5}{|c|}{ Período seco } \\
\hline Normais & 11,82 & {$[11,41 ; 12,18]$} & 2,91 & - & - \\
\hline 2005 & 12,05 & {$[11,60 ; 12,47]$} & 2,25 & $+1,95$ & $<0,001$ \\
\hline \multirow[t]{2}{*}{2010} & 11,27 & {$[10,94 ; 11,60]$} & 1,56 & $-4,65$ & $<0,001$ \\
\hline & \multicolumn{5}{|c|}{ Período seco-úmido } \\
\hline Normais & 11,32 & {$[10,88 ; 11,77]$} & 3,81 & - & - \\
\hline 2005 & 12,87 & {$[12,09 ; 13,71]$} & 3,32 & $+13,69$ & $<0,001$ \\
\hline 2010 & 11,45 & {$[10,71 ; 12,17]$} & 3,49 & $+1,15$ & $<0,001$ \\
\hline
\end{tabular}

Notas: $\bar{x}$ - média; IC - intervalo de confiança; s - desvio padrão; p-valor - nível de significância observado. O p-valor foi calculado por meio de teste de hipótese entre os anos extremos e os anos normais. Dados indisponíveis foram substituídos por hífen (-).

namento de carbono, podendo futuramente interferir no aproveitamento energético.

Os eventos de seca ocorridos em 2005 e 2010 proporcionaram aumento significativo no saldo de radiação ( $\mathrm{p}$-valor $<0,001$ ), principalmente no período úmido-seco, em resposta à menor cobertura de nuvens. Esse resultado pôde ser observado em ambos os locais de estudo e está de acordo com os dados apresentados por Oliveira (2014), o qual mostra baixa precipitação para o período úmido-seco dos anos de 2005 e 2010 nesses mesmos locais.

A ocorrência do evento de seca em 2005 proporcionou redução do saldo de radiação na área de pastagem 
(Tabela 8). A captação da radiação solar pelas plantas permite a fixação e espalhamento do carbono em suas estruturas e a quantidade de luz determina a eficiência do processo fotossintético. Assim, a redução da disponibilidade do saldo de energia e a alteração das porcentagens de calor latente e calor sensível em decorrência de secas severas, pode afetar negativamente as pastagens, uma vez que seu desenvolvimento será comprometido (Santos; Zonetti, 2009), comprometendo, consequentemente, a dieta dos animais ruminantes. Esse pode ser considerado um efeito negativo para as áreas de pastagem.

A área de floresta apresentou saldo de radiação superior ao da pastagem em toda a série de estudo (Tabela 9). Para o período úmido de anos normais foi constatada diferença altamente significativa de $-20,51 \%$ (p-valor < 0,001 ) entre o saldo de radiação da área de floresta e da pastagem, enquanto que no ano de 2010 a diferença apresentada no mesmo período foi de $-12,91 \%$. Essa redução na diferença entre os dois sítios deve-se ao aumento do saldo de radiação no sítio de pastagem em relação aos anos normais, causado, provavelmente, pela redução da cobertura de nuvens.

Ao comparar as áreas estudadas entre anos normais e anos com ocorrência de eventos extremos por período (Tabelas 7 e 8) é possível observar que os eventos extremos influenciaram mais fortemente a área de floresta do que a área de pastagem. As áreas de pastagem são mais vulneráveis às queimadas, o que aumenta a concentração de aerossóis atmosféricos e, por conseguinte, influencia diretamente no saldo de radiação que chega à superfície desses locais.

As áreas florestais, por sua vez, são menos propensas às queimadas e por isso têm seu saldo de radiação influenciado principalmente pelas condições atmosféricas. Por isso, a menor cobertura de nuvens durante os anos de 2005 e 2010 em decorrência dos eventos de seca proporcionaram aumento do saldo de radiação de forma mais evidente no sítio de floresta.

No período seco, também foi observada expressiva diferença entre os sítios. Os anos normais apresentaram diferença altamente significativa de $-21,07 \%$ (p-valor < $0,001)$ e os anos extremos apresentaram diferença significativa de $-25,89 \%$ e $-16,42 \%$ nos anos de 2005 e 2010 , respectivamente. $\mathrm{O}$ aumento da diferença entre os sítios no ano de 2005 foi causado por uma redução no saldo de radiação do sítio de pastagem, comparado com os anos normais, o que corrobora com a hipótese de ter ocorrido maior influência das queimadas na quantidade de irradiância solar global que chega à superfície no sítio de pastagem.

Adicionalmente, o déficit hídrico sofrido pelas gramíneas no período seco tende a alterar a coloração das folhas, ocasionando maior refletividade na radiação incidente, o que torna menos eficiente a absorção de radiação. As árvores da Floresta Amazônica, ao contrário, são capazes de manter a estrutura das suas copas com alto grau de coloração verde mesmo durante a estação seca (Morton, et al., 2014). Por outro lado, no ano de 2010, a redução da diferença dos saldos de radiação entre os sítios estudados

Tabela 8 - Valores médios de saldo de radiação $\left(\mathrm{MJ} \mathrm{m}^{-2} \mathrm{dia}^{-1}\right)$ por período em diferentes anos no sítio de pastagem, medidas descritivas, diferença ao comparar os anos de extrema seca (2005 e 2010) com os normais $(2004,2006,2007$ e 2008) e os respectivos testes de hipótese de comparação de médias $(\alpha=0,05)$.

\begin{tabular}{|c|c|c|c|c|c|}
\hline Anos & $\bar{x}$ & IC & s & Diferença (\%) Anos extremos/anos normais & $\mathrm{p}$-valor \\
\hline & \multicolumn{5}{|c|}{ Período úmido } \\
\hline Normais & 8,37 & {$[8,02 ; 8,76]$} & 3,53 & - & - \\
\hline 2005 & 9,18 & {$[8,43 ; 9,95]$} & 3,62 & $+9,68$ & $<0,001$ \\
\hline \multirow[t]{2}{*}{2010} & 9,11 & {$[8,37 ; 9,83]$} & 3,52 & $+8,84$ & $<0,001$ \\
\hline & \multicolumn{5}{|c|}{ Período úmido-seco } \\
\hline Normais & 8,65 & {$[8,35 ; 8,90]$} & 2,68 & - & - \\
\hline 2005 & 9,01 & {$[8,47 ; 9,55]$} & 2,57 & $+4,16$ & $<0,001$ \\
\hline \multirow[t]{2}{*}{2010} & 8,97 & {$[8,46 ; 9,44]$} & 2,29 & $+3,70$ & $<0,001$ \\
\hline & \multicolumn{5}{|c|}{ Período seco } \\
\hline Normais & 9,33 & {$[9,10 ; 9,57]$} & 2,04 & - & - \\
\hline 2005 & 8,93 & {$[8,45 ; 9,39]$} & 2,34 & $-4,29$ & $<0,001$ \\
\hline \multirow[t]{2}{*}{2010} & 9,42 & {$[8,80 ; 10,00]$} & 2,98 & $+0,96$ & $<0,001$ \\
\hline & \multicolumn{5}{|c|}{ Período seco-úmido } \\
\hline Normais & 9,68 & {$[9,24 ; 10,09]$} & 3,37 & - & - \\
\hline 2005 & 9,66 & {$[8,73 ; 10,53]$} & 3,61 & $-0,21$ & - \\
\hline 2010 & 9,76 & {$[8,50 ; 11,00]$} & 3,56 & $+0,83$ & $<0,001$ \\
\hline
\end{tabular}

Notas: $\bar{x}$ - média; IC - intervalo de confiança; s - desvio padrão; p-valor - nível de significância observado. O p-valor foi calculado por meio de teste de hipótese entre os anos extremos e os anos normais. Dados indisponíveis foram substituídos por hífen (-). 
Tabela 9 - Valores médios de saldo de radiação ( $\mathrm{MJ} \mathrm{m}^{-2}$ dia $\left.^{-1}\right)$ por período em anos normais $(2004,2006,2007$ e 2008$)$ e de extrema seca (2005 e 2010) nos sítios de floresta (Rebio Jaru) e de pastagem (FNS), diferença ao comparar os sítios experimentais e respectivos testes de hipótese de comparação de médias $(\alpha=0,05)$.

\begin{tabular}{|c|c|c|c|c|}
\hline \multirow[t]{2}{*}{ Período } & \multicolumn{2}{|c|}{$\bar{x}$} & Diferença (\%) FNS/Rebio Jaru & \multirow[t]{2}{*}{ p-valor } \\
\hline & Rebio Jaru & FNS & & \\
\hline & \multicolumn{4}{|c|}{ Anos normais } \\
\hline Úmido & 10,53 & 8,37 & $-20,51$ & $<0,001$ \\
\hline Úmido-seco & 10,03 & 8,65 & $-13,76$ & $<0,001$ \\
\hline Seco & 11,82 & 9,33 & $-21,07$ & $<0,001$ \\
\hline \multirow[t]{2}{*}{ Seco-úmido } & 11,32 & 9,68 & $-14,49$ & $<0,001$ \\
\hline & \multicolumn{4}{|c|}{2005} \\
\hline Úmido & - & 9,18 & - & - \\
\hline Úmido-seco & 11,26 & 9,01 & $-19,98$ & $<0,001$ \\
\hline Seco & 12,05 & 8,93 & $-25,89$ & $<0,001$ \\
\hline \multirow[t]{2}{*}{ Seco-úmido } & 12,87 & 9,66 & $-24,94$ & $<0,001$ \\
\hline & \multicolumn{4}{|c|}{2010} \\
\hline Úmido & 10,46 & 9,11 & $-12,91$ & $<0,001$ \\
\hline Úmido-seco & 11,46 & 8,97 & $-21,73$ & $<0,001$ \\
\hline Seco & 11,27 & 9,42 & $-16,42$ & $<0,001$ \\
\hline Seco-úmido & 11,45 & 9,76 & $-14,76$ & $<0,001$ \\
\hline
\end{tabular}

Notas: $\bar{x}$ - média; p-valor - nível de significância observado. O p-valor foi calculado por meio de teste de hipótese entre os sítios de floresta e de pastagem. Dados indisponíveis foram substituídos por hífen (-).

deve-se a uma diminuição no saldo de radiação do sítio de floresta comparado aos valores obtidos em anos normais.

Além disso, a concentração de aerossóis provenientes de queimadas é maior em áreas de pastagem do que em ecossistemas florestais, o que também colabora para maior saldo radiativo no sítio de floresta. Esses aerossóis afetam os processos microfísicos das nuvens, reduzindo o tamanho das gotículas de água nas nuvens devido à maior quantidade de aerossóis que agem como núcleos de condensação, reduzindo a precipitação local e aumentando o tempo de vida da nuvem (Davidson et al., 2012), o que, consequentemente, reduz a radiação solar que chega à superfície.

Em toda a série estudada foi possível observar que a área de floresta apresentou menores valores de desvio padrão comparada à pastagem (Tabelas 7 e 8), resultado similar ao encontrado por Biudes et al. (2015). Esse comportamento surge em função das características das Florestas Amazônicas como o menor albedo, maior umidade e maior índice de área foliar que permitem maior absorção da luz solar.

Além disso, áreas florestais possuem maior biomassa, o que reduz a temperatura do dossel e a emissão de radiação de onda longa pelo dossel, proporcionando maior saldo de radiação (Biudes et al., 2015). Esse comportamento evidencia a maior adaptabilidade da Floresta Amazônica aos eventos extremos de seca, frente às áreas de pastagem, ajudando a regular o clima regional e proporcionando um ambiente mais propício para a vida humana em seu entorno.
De modo geral, os riscos para a agricultura e as atividades pecuaristas estão relacionadas ao aumento da temperatura média do ar, redução da precipitação e mudança espaço-temporal dos eventos de precipitação. Em conjunto ou de forma individual, tais fatores podem reduzir significativamente o rendimento agrícola. Os extremos climáticos representam risco ao alterar a temperatura do ar e/ou a precipitação.

\section{Considerações Finais}

A ocorrência de eventos extremos na Região Amazônica nos anos de 2005 e 2010 afetou o padrão sazonal das variáveis meteorológicas, alterando significativamente a umidade específica do ar, temperatura do ar e saldo de radiação. Em ambas áreas de estudo a umidade específica do ar foi significativamente reduzida nos períodos seco e seco-úmido, enquanto a temperatura do ar e saldo de radiação sofreram aumento em todos os períodos do ano. Os resultados foram mais evidentes na área de pastagem, indicando maior vulnerabilidade desse ecossistema.

Esses resultados corroboram o quanto a conversão de áreas de floresta para pastagem aliada aos eventos extremos que vêm ocorrendo na Região Amazônia pode interferir nas variáveis meteorológicas, de modo que é imprescindível o contínuo estudo dessa dinâmica para que as implicações para o clima local, regional e global sejam elucidadas. 


\section{Agradecimentos}

Agradecemos à PROPesq/UNIR e ao CNPq por ter possibilitado o desenvolvimento dessa pesquisa através da concessão de bolsa de iniciação científica e ao Programa LBA pela disponibilização dos dados.

\section{Referências}

ARTAXO, P.; DIAS, M.A.F.S.; NAGY, L.; LUIZÃO, F.J.; CUNHA, H.B.; QUESADA, C.A.N.; MARENGO, J.A.; KRUSCHE, A. Perspectivas de pesquisas na relação entre clima e o funcionamento da floresta amazônica. Ciência e Cultura, v. 66, n. 3, p. 41-46, 2014.

BIUDES, M.S.; VOURLITIS, G.L.; MACHADO, N.G.; ARRUDA, P.H.Z.; NEVES, G.A.R.; LOBO, F.A.; NEALE, C.M.U.; NOGUEIRA, J.S. Patterns of energy exchange for tropical ecosystems across a climate gradient in Mato Grosso, Brazil. Agricultural and Forest Meteorology, v. 202, p. 112-124, 2015.

BORMA, L.D.S.; NOBRE, C.A.; CARDOSO, M. Response of the Amazon Tropical Forests to Deforestation, Climate, and Extremes, and the Occurrence of Drought and Fire. In: PIELKE, R.A. (Ed.). Climate Vulnerability: Understanding and Addressing Threats to Essential Resources. Academic Press: Cambridge, p. 153-163, 2013.

COELHO, C.A.S.; CAVALCANTI, I.A.F.; COSTA, S.M.S.; FREITAS SAULO R.; ITO, E.R.; LUZ, G.; SANTOS, A.F.; NOBRE, C.A.; MARENGO, J.A.; PEZZA, A.B. Climate diagnostics of three major drought events in the Amazon and illustrations of their seasonal precipitation predictions. Meteorological Applications, v. 19, p. 237$255,2012$.

CULF, A.D.; FISCH, G.; MALHI, Y.; NOBRE, C.A. The influence of the atmospheric boundary layer on carbon dioxide concentrations over a tropical forest. Agricultural and Forest Meteorology, v. 85, p. 149-158, 1997.

DAVIDSON, E.A.; ARAÚJO, A.C.; ARTAXO, P.; BALCH, J.K.; BROWN, I.F.; BUSTAMANTE, M.M.C.; COE, M.T.; DEFRIES, R.S.; KELLER, M.; LONGO, M.; MUNGER, J.W.; SCHROEDER, W.; SOARES-FILHO, B.S.; SOUZA JR, C.M.; WOFSY, S.C. The Amazon basin in transition. Nature, v. 481, p. 321-328, 2012.

FEARNSIDE, P.M. A vulnerabilidade da floresta amazônica perante as mudanças climáticas. Oecologia Brasiliensis, v. 13, n. 4, p. 609-618, 2009.

FRANCA, R.R. Climatologia das chuvas em Rondônia - período 1981-2011. Geografias, v. 11, n. 1, p. 44-58, 2015.

GOMES, J.B.; WEBLER, A.D.; AGUIAR, R.G.; AGUIAR. L.J.G.; NUÑES, M.L.A. Conversão de florestas tropicais em sistemas pecuários na Amazônia: Quais as implicações no microclima da região? Revista Brasileira de Climatologia, v. 17, n. 11, p. 67-81, 2015.

HARRIS, P.P.; HUNTINGFORD, C.; COX, P.M. Amazon basin climate under global warming: the role of the sea surface temperature. Philosophical Transactions of the Royal Society, v. 363, p. 1753-1759, 2008.

INSTITUTO NACIONAL DE PESQUISAS ESPACIAIS. Seca de 2010 na Amazônia foi a mais drástica já registrada.
INPE, 2011. Disponível em: www.inpe.br/noticias/ noticia. php?Cod_Noticia=2639. Acesso em: 18 de fev. 2016.

INTERGOVERNMENTAL PANEL ON CLIMATE CHANGE IPCC. Climate Change 2014: Mitigation of Climate Change. Contribution of Working Group III to the Fifth Assessment Report of the Intergovernmental Panel on Climate Change. Cambridge University Press: Cambridge, 1435 p. 2014.

LAWRENCE, D.; VANDECAR, K. Effects of tropical deforestation on climate and agriculture. Nature Climate Change, v. 5, p. 27-36, 2015.

LI W.; FU, R.; DICKINSON, R.E.; Rainfall and its seasonality over the Amazon in the 21st century as assessed by the coupled models for the IPCC AR4. Journal of Geophysical Research, v. 111, p. 1-14, 2006.

MARENGO, J.A.; BORMA, L.S.; RODRIGUEZ, D.A.; PINHO, P.; SOARES, W.R.; ALVES, L.M. Recent extremes of drought and flooding in Amazonia: Vulnerabilities and human adaptation. American Journal of Climate Change, v. 2, p. 87-96, 2013.

MARENGO, J.A.; NOBRE, C.A., TOMASELLA, J., OYAMA, M.D., OLIVEIRA, G.S., OLIVEIRA, R., CAMARGO, H.; ALVES, L.M.; BROWN, I.F. The drought of Amazonia in 2005. Journal of Climate, v. 21, p. 495-516, 2008.

MARENGO, J.A.; TOMASELLA, J.; ALVES, L.M.; SOARES, W.R.; RODRIGUEZ, D.A. The drought of 2010 in the context of historical droughts in the Amazon region. Geophysical Research Letters, v. 38, L12703, 2011a.

MARENGO, J.A.; TOMASELLA, J.; SOARES, W.R.; ALVES, L.M.; NOBRE, C.A. Extreme climatic events in the Amazon basin. Theoretical and Applied Climatology, v. 107, p. 73-85, 2011b.

MINITAB. Minitab 17. State College, 2010. Disponível em: www.minitab.com/ptBR/default.aspx. Acesso em: $14 \mathrm{de}$ set. 2016.

MORTON, D.C.; NAGOL, J.; CARABAJAL, C.C.; ROSETTE, J.; PALACE, M.; COOK, B.D.; VERMOTE, E.F.; HARDING, D.J.; NORTH, P.R.J. Amazon forests maintain consistent canopy structure and greenness during the dry season. Nature, v. 506, p. 221-224, 2014.

NEGRÓN-JUARÉZ, R.I.; HODNETT, M.G.; FU, R.;GOULDEN, M.L.; VON RANDOW, C. Control of dry season evapotranspiration over the Amazonian forest as inferred from observations at a Southern Amazon forest site. Journal of Climate, v. 20, p. 2827-2839, 2007.

NEPSTAD, D.C.; CARVALHO, C.R.; DAVIDSON, E.A.; JIPP, P.H.; LEFEBVRE, P.A.; NEGREIROS, G.H.; SILVA, E.D.; STONE, T.A.; TRUMBORE, S.E.; VIEIRA, S. The role of deep roots in the hydrological and carbon cycles of Amazonian forests and pastures. Nature, v. 372, p. 666-669, 1994.

OLIVEIRA, M.A. Caracterização da precipitação em área de floresta e pastagem no Sudoeste da Amazônia. Monografia. Departamento de Matemática e Estatística, Universidade Federal de Rondônia, 2014.

RUMMEL, U.; AMMANN, C.; GUT, A.; MEIXNER, F.X.; ANDREAE, M.O. Eddy covariance measurements of nitric oxide flux within an Amazonian rain forest. Journal of Geophysical Research, v. 107, p. 171-179, 2002. 
SANTOS, G.A.; ZONETTI, P.C. Influência da temperatura na germinação e desenvolvimento do girassol (Helianthus annuus L.). Iniciação Científica CESUMAR, v. 11, n. 1, p. 23-27, 2009.

SILVA-DIAS, M.A.F. Eventos climáticos extremos. Revista USP, n. 103, p. 33-40, 2014.

TAVARES, J.P.N. Interação entre a vegetação e a atmosfera para formação de nuvens e chuva na Amazônia: uma revisão. Estudos Avançados, v. 26, n. 74, p. 219-227, 2012.

VON RANDOW, C.; MANZI, A.O.; KRUIJT, B.; OLIVEIRA, P.J.; ZANCHI, F.B.; SILVA, R.L.; HODNETT, M.G.; GASH, J.H.C.; ELBERS, J.A.; WATERLOO, M.J.; CARDOSO, F.L.; KABAT, P. Comparative measurements and seasonal variations in energy and carbon exchange over forest and pasture in South West Amazonia. Theoretical and Applied Climatology, v. 78, p. 5-26, 2004.

WANG, J.; KREJCI, R.; GIANGRANDE, S.; KUANG, C.; BARBOSA, H.M.J.; BRITO, J.; CARBONE, S.; CHI, X.;
COMSTOCK, J.; DITAS, F.; LAVRIC, J.; MANNINEN, H.E.; MEI, F; MORAN-ZULOAGA, D.; PÖHLKER, C.; PÖHLKER, M.L.; SATURNO, J.; SCHMID, B.; SOUZA, R.A.F.; SPRINGSTON, S.R.; TOMLINSON, J.M.; TOTO, T.; WALTER, D.; WIMMER, D.; SMITH, J.N.; KULMALA, M.; MACHADO, L.A.T.; ARTAXO, P.; ANDREAE, M.O.; PETÄJÄ, T.; MARTIN, S.T. Amazon boundary layer aerosol concentration sustained by vertical transport during rainfall. Nature, v, 539, p. 416-419, 2016.

WEBLER, A.D.; GOMES, J.B.; AGUIAR, R.G.; ANDRADE, N.L.R.; AGUIAR, L.J.G. Mudanças no uso da terra e o particionamento de energia no sudoeste da Amazônia. Revista Brasileira de Engenharia Agrícola e Ambiental, v. 17, n. 8, p. 868-876, 2013.

License information: This is an open-access article distributed under the terms of the Creative Commons Attribution License (type CC-BY), which permits unrestricted use, distribution and reproduction in any medium, provided the original article is properly cited. 